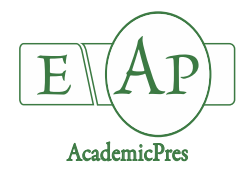

Guo S et al. (2020)

Notulae Botanicae Horti Agrobotanici Cluj-Napoca 48(2):626-635

DOI: $10.15835 /$ nbha 48211634

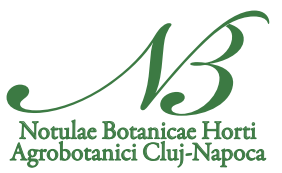

\title{
Root growth of Eleuthero (Eleutherococcus senticosus [Rupr. \& Maxim.] Maxim.) seedlings cultured with chitosan oligosaccharide addition under different light spectra
}

\author{
Shenglei GUO ${ }^{a}$, Shuang ZHANG ${ }^{\mathrm{b}}$, Liwei JIA, Mingyuan XU, \\ Zhenyue WANG*
}
Laboratory of Chinese Medicine Resource, Heilongjiang University of Chinese Medicine, Harbin 150040, China; guoshenglei@163.com; rocmsw@163.com;wsjlw@163.com;xumingyuan2000@163.com;wangzhen_yue@163.com ('corresponding author)
${ }^{a, b}$ These authors contributed equally to this work

\begin{abstract}
Eleuthero (Eleutherococcus senticosus [Ruprecht \& Maximowicz] Maximowicz is an important understory species as well as a source of natural products in Asia. The natural source of Eleuthero has been over exploited for pharmacological use, but the manual restoration to rehabilitate its natural distribution has not yet been established. The root is one of the main underground organs in Eleuthero for the acquisition of pharmaceutical ingredients. Root growth also determines the seedling quality of this species for ecological restoration. In this study, Eleuthero seedlings were cultured for one growing cycle with chitosan oligosaccharide (CO) addition at rates of 0 and $25 \mathrm{ppm}$ under artificial lightings by high-pressure sodium (HPS) lamps and two light-emitting diodes (LEDs) with photosynthetic photon flux density set to $94 \pm 5 \mu \mathrm{mol} \mathrm{m}{ }^{-2}$. Light spectra of red $(R)$ : green $(G)$ : blue $(B)$ ratios were measured to be 43.7:54.6:1.7, 43.8:47:9.2, and 72.7:13.3:14 for the HPS, LED-1, and LED-2 treatments, respectively. In autumn, no interactive effect was found between CO addition and light spectra treatments on any root parameters. Compared to the HPS treatment, the LED-1 treatment resulted in a greater root dry weight and morphology by over $30 \%$. The CO addition caused an increase of root growth by $40-70 \%$. Fine roots in diameter between $0-0.4 \mathrm{~mm}$ were the main root part that contributed to the length, surface area, and root tip number. Therefore, LED lighting with the R/G/B spectrum of 43.8:47:9.2 was suggested for the culture of Eleuthero seedlings with the purpose of promoting dry weight and morphology of fine roots.
\end{abstract}

Keywords: artificial illumination; Ciwujia; natural product; Northeast China; underground organ

\section{Introduction}

The Eleutherococcus Maxim. [Acanthopanax (Decne. et Planch) Witte] genus comprises about 40 species, most of which are naturally distributed in Eastern Asia and Far East Russia (Wan et al., 2016; Zaluski and Smolarz, 2016). Eleutherococcus senticosus (Eleuthero) is the only species from the Eleutherococcus family that was documented by the European Pharmacopoea and American Herbal Pharmacopoeia monographs 
(Zaluski and Smolarz, 2016). Forests in Northeast China account for a large area of the natural Eleuthero reserves (Guo et al., 2019). Eleuthero naturally distributes as a long-lived shrub in broad-leaved and mixed broadleaf-conifer forests. Underground organs of Eleuthero contain multiple antioxidants and pharmacological ingredients (Zhai et al., 2017). However, the over-exploitation of Eleuthero has almost wiped out its natural reserves in Northeast China (Zhai et al., 2017). Climate change has also contributed to the shift and decline of its natural distribution (Wan et al., 2016; Guo et al., 2019). Therefore, it is necessary to restore the natural source of Eleuthero through artificial restoration.

The seedling quality can be measured by attributes at the end of culture and can be used to forecast transplant performance (Duan et al., 2013; Wei et al., 2013a). A larger root system can elicit better root growth potential which is achieved through prolonged photoperiod by high-pressure sodium (HPS) lamps (Wei et al., 2013b; Zhu et al., 2016; Zhao et al., 2017; Li et al., 2017a). Light emitting diode (LED) technique can further promote seedling quality using designed spectrums (Li et al., 2017a, 2018; Zhao et al., 2019; Wei et al., 2020). The LED spectrum can induce growth and biomass accumulation in underground organs of vegetation. For example, red (R; 600-700 nm) light was found to depress root growth in tomato (Solanum lycopersicum L. cv. SV0313TG) seedlings (Li et al., 2017b) but favour root biomass in larch (Larix principis-rupprechtii Mayr.) (Zhao et al., 2019) and pine (Pinus koraiensis) seedlings (Wei et al., 2020). Evidence also exists that root biomass in Dalbergia odorifera is not responsive to light spectra (Li et al., 2018). These reports demonstrate the need to test spectra effect on root growth in Eleuthero.

Chitosan is generated from chitin ( $\beta-1.4-\mathrm{N}$-acetylglucosamine) by deacetylation, which can be derived from the shells of marine animals. Chitosan oligosaccharide $(\mathrm{CO})$ has been widely used as a plant growth modifier for several crop and woody species (Khan et al., 2002; Jeong and Park, 2005; Wang et al., 2017; Li et al., 2018). Rhizosphere moisture can be reserved by substrate and contributes to the application of $C O$ addition through root soaking (Wang et al., 2017; Li et al., 2018). The CO addition to root has been found to promote new root number in over-year Buddhist pine (Podocarpus macrophyllus) seedlings (Wang et al., 2017), but it barely affects root biomass in fragrant rosewood ( $D$. odorifera) seedlings unless it is paired with the manipulation of light spectra ( $\mathrm{Li}$ et al., 2018). Therefore, the addition of CO may be used as a root-growth promoter for Eleuthero plants and should be tested with combined lighting spectra.

The purpose of the current study was to test the response of fine root growth of Eleuthero seedlings to combined treatments to the combined treatment of LED spectra and CO addition. We hypothesized that: (i) the root growth can be enhanced by combined effects of $\mathrm{CO}$ addition and light spectra, and (ii) fine root morphology with very fine diameters would respond.

\section{Materials and Methods}

\section{Plant material}

The study was conducted on Heilongjiang University of Chinese Medicine (45 43'34.66" N, $126^{\circ} 38^{\prime} 44.12^{\prime \prime}$ E), Harbin, Heilongjiang, China. Seeds of Eleuthero (Eleutherococcus senticosus [Ruprecht \& Maximowicz] Maximowicz were collected from a seed orchard at Qitaihe $\left(45^{\circ} 37^{\prime} \mathrm{N}, 31^{\circ} 15^{\prime} \mathrm{E}\right)$, Heilongjiang, China in the autumn of 2016. In early February of 2017, seeds were sterilized in potassium permanganate $(0.5$ $\%, \mathrm{w} / \mathrm{w}$ ) for $5 \mathrm{~min}$, soaked in distilled water for $12 \mathrm{~h}$, and sowed in trays filled with sterilized sands for germination. Seeds were germinated in an incubation chamber where the condition was set at a range of 34/22 ${ }^{\circ} \mathrm{C}(\mathrm{max} / \mathrm{min})$ for temperature with air humidity of $80 \%$ in a $16 \mathrm{~h}$ photoperiod (spectrum of $16.6 \% \mathrm{red}, 75 \%$ green [G; 500-600 nm], and 8.4\% blue [B; 400-500 nm] lights as $70 \mu \mathrm{mol} \mathrm{m}^{-2} \mathrm{~s}^{-1}$ ) (Wang et al., 2018). Three months after germination, seedlings of similar size were transplanted into plastic pots $(7 \mathrm{~cm}$ in height, $13 \mathrm{~cm}$ in diameter) which were filled with substrates (Mushro-Dust ${ }^{\circ}$, Zhiluntuowei Agric. S\&T Ltd., Changchun, 
China) mixing peat, perlite, and controlled-release fertilizers (CRFs) $(3: 1: 0.1, \mathrm{v} / \mathrm{v} / \mathrm{v})$. Each of the grouped pots was placed in one tank $(35 \mathrm{~cm} \times 55 \mathrm{~cm})$ with the initial water table at the height of $6 \mathrm{~cm}$.

\section{Lighting spectra treatment}

One week after transplant, potted seedlings were randomly arranged and placed into four replicated blocks $(40 \mathrm{~cm} \times 120 \mathrm{~cm})$ on mobile seedbeds in a greenhouse. An LED lighting panel with an area of $0.66 \mathrm{~m}^{2}$ $(55 \mathrm{~cm} \times 120 \mathrm{~cm}$ ) was placed at the height of $80 \mathrm{~cm}$. Two spectra were supplied by LEDs (LED-1, percent R/G/B, 43.8:47:9.2; LED-2, percent R/G/B, 72.7:13.3:14) with another by HPS (percent R/G/B, 43.7:54.6:1.7) as the control at a photosynthetic photon flux density (PPFD) at $94 \pm 5 \mu \mathrm{mol} \mathrm{m}^{-2} \mathrm{~s}^{-1}$ at $55 \mathrm{~cm}$ height. Lighting was controlled in a 16-h photoperiod from 5:00 am to 21:00 pm. Throughout the experiment, relative humidity $(\mathrm{RH})$ and temperature were monitored to be $70 \pm 10 \%$ and $25 / 18{ }^{\circ} \mathrm{C}$ (day/night), respectively.

\section{The CO treatment}

A tank was watered with CO solution (Qishanbao', GlycoBio Co., Ltd., Dalian, China) at the concentration of $25 \mathrm{ppm}$, with distilled water in another tank. The CO treatment started at the same time with the lighting spectra treatment and was implemented every two weeks. Seedlings were cultured by commercial substrates wherein roots were fed by micro-nutrients $\left(\mathrm{N}-\mathrm{P}_{2} \mathrm{O}_{5}-\mathrm{K}_{2} \mathrm{O}, 10-4-7\right)$ from CRFs continuously for four months. Therefore, each seedling received $80 \mathrm{mg}$ nitrogen $(\mathrm{N})$ during culture, no extra nutrients were supplied.

\section{Root sampling and measurement}

Roots were sampled on the $15^{\text {th }}$ September, 2017 at the end of culture. Four seedlings were randomly chosen and harvested from one combined treatment per block. Root samples were further divided by every first-order lateral root and scanned to obtain plane image (Epson Expression 10000XL, Japan). Scanned images were analysed using the WinRHIZO software (Regent Instruments Inc., Canada) for average root diameter $(\mathrm{mm})$, total root length $(\mathrm{cm})$, total root surface area $\left(\mathrm{cm}^{2}\right)$, and number of root tips for the whole root system and in each of the 10 diameter classes (from 0 to $0.9 \mathrm{~mm}$ by every $0.1 \mathrm{~mm}$ and $>0.9 \mathrm{~mm}$ ). Post-scanned root samples were oven-dried at $70^{\circ} \mathrm{C}$ for two days and measured for dry weight.

\section{Statistical analysis}

Statistical tests and analyses were performed using the SPSS software (Ver. 19.0, IBM statistics, Chicago, U.S.A.) and graphs were generated using the SigmaPlot software (Ver. 11.0, Systat Software Inc., GmbH, Germany). All root data passed the normality test (Kolmogorov-Smirnov method). The two-way analysis of variance (ANOVA) was conducted on all root parameters to test the combined effects of lighting spectra and $\mathrm{CO}$ addition. When the interactive effect was detectable all results were compared by the one-way ANOVA with four replicates $(n=4)$. Otherwise, the results were compared by the main effect of light spectra $(n=8)$ or $\mathrm{CO}$ addition $(n=12)$. The significance was identified at the $P<0.05$ level according to Duncan test. In order to analyse the relationship among root morphological parameters in different diameter classes, data of root length, surface area, and tip number were analysed by the principle component analysis (PCA) method. Coupled correlations were analysed between root dry weight and every fine root morphology.

\section{Results}

Effects of $C O$ addition and light spectra on root growth

Effects of light spectra and CO addition had no combined effects on root biomass and morphology in Eleuthero seedlings (Table 1). Instead, either of the two treatments had a significant main effect on root parameters. Among the three light spectra, the LED-1 treatment resulted in better root growth than in the 
HPS treatment. Compared to the HPS treatment, seedlings under the LED-1 spectrum had greater root length, surface area, diameter, tip number, and dry weight by $79 \%, 71 \%, 36 \%, 55 \%$, and $77 \%$, respectively (Figure 1). However, root growth in seedlings in the two spectra treatments had no difference. The CO addition increased root growth by $73 \%, 68 \%, 47 \%, 58 \%$, and $65 \%$ in length, surface area, diameter, tip number, and dry weight, respectively (Figure 1).

Table 1. $F$ values from ANOVA analysis of light spectrum (L), chitosan oligosaccharide $(\mathrm{CO})$ addition, and their interaction $(\mathrm{L} \times \mathrm{CO})$ on fine root morphology in Eleuthero (Eleutherococcus senticosus Ruprecht \& Maximowicz] Maximowicz)

\begin{tabular}{|c|c|c|c|c|c|c|}
\hline $\begin{array}{c}\text { Source of } \\
\text { variation }\end{array}$ & $\mathrm{DF}^{\mathrm{a}}$ & $\begin{array}{c}\text { Root } \\
\text { length }\end{array}$ & $\begin{array}{c}\text { Surface } \\
\text { area }\end{array}$ & Diameter & $\begin{array}{c}\text { Tip } \\
\text { number }\end{array}$ & $\begin{array}{c}\text { Dry } \\
\text { weight }\end{array}$ \\
\hline $\mathrm{L}$ & 2 & $25.31^{* * *} \mathrm{~b}$ & $21.53^{* * *}$ & $13.18^{* * *}$ & $12.24^{* * *}$ & $27.16^{* * *}$ \\
\hline $\mathrm{CO}$ & 1 & $36.99^{* * *}$ & $38.27^{* * *}$ & $18.94^{* * *}$ & $19.75^{* * *}$ & $40.62^{* * *}$ \\
\hline $\mathrm{L} \times \mathrm{CO}$ & 2 & 2.43 & 2.32 & 1.96 & 2.26 & 0.50 \\
\hline
\end{tabular}

${ }^{\mathrm{a}} \mathrm{DF}$, degree of freedom; ${ }^{\mathrm{b} * * *}$, significance at the level $<0.001$.
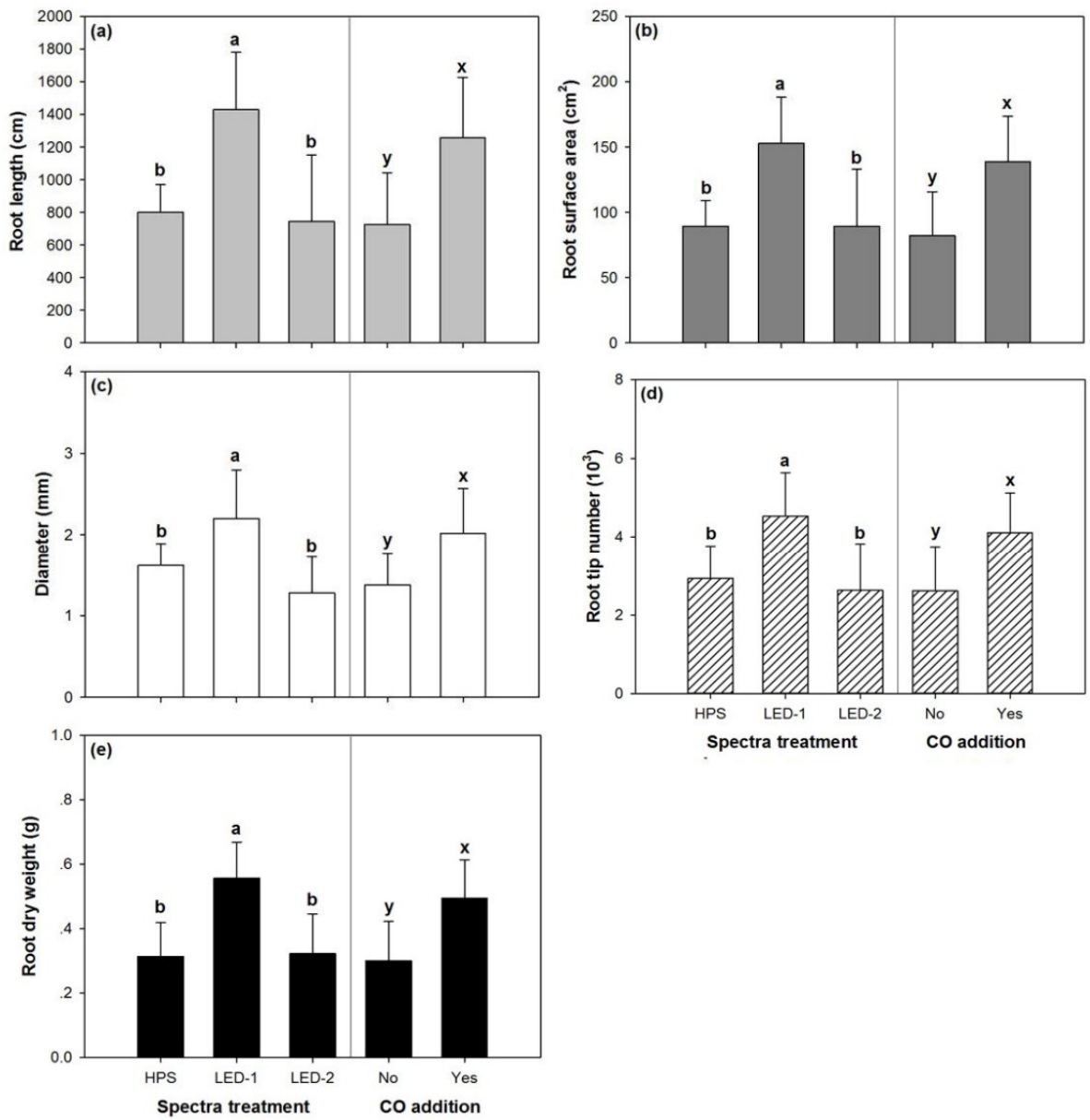

Figure 1. Root growth parameters of length (a), surface area (b), diameter (c), tip number (d), and dry weight (e) in Eleuthero (Eleutherococcus senticosus [Ruprecht \& Maximowicz] Maximowicz) seedlings with chitosan oligosaccharide (CO) addition at rates of 0 (No) and $25 \mathrm{ppm}$ (Yes) under light spectra from highpressure sodium (HPS) lamps and two light-emit diodes (LEDs) panels. Different letters indicate significant difference among treatments. Lowercase letters of a, b, and $c$ are labeled for light spectra treatment, and those of $\mathrm{x}$ and $\mathrm{y}$ are labeled for $\mathrm{CO}$ addition treatment 


\section{The response of fine root morphology in different diameter classes}

Effects of light spectra and CO addition had no interactive effects on any fine root morphological parameters in any diameter classes (Figure 2). Similar to results about whole root system, fine root morphology was also higher with CO addition and highest in the LED-1 treatment among the three light spectra treatments, although significant results did not always persist in any diameter classes. Among the spectra treatments, fine root length was highest in the LED-1 treatment in all diameter classes except for the diameter of 0-0.1 mm (Figure 2a). However, CO addition increased fine root length in all diameter classes (Figure 2b). Root surface area was highest in the LED-1 treatment in all diameter classes except for the largest, which was more than $0.9 \mathrm{~mm}$ (Figure 2c). CO addition also increased surface area in all fine root diameter classes (Figure 2d). Root tip number only responded to light spectra in diameter classes between 0.1 and $0.5 \mathrm{~mm}$ (Figure 2e), while it responded to the $\mathrm{CO}$ addition only in diameter classes less than $0.3 \mathrm{~mm}$ (Figure 2f).
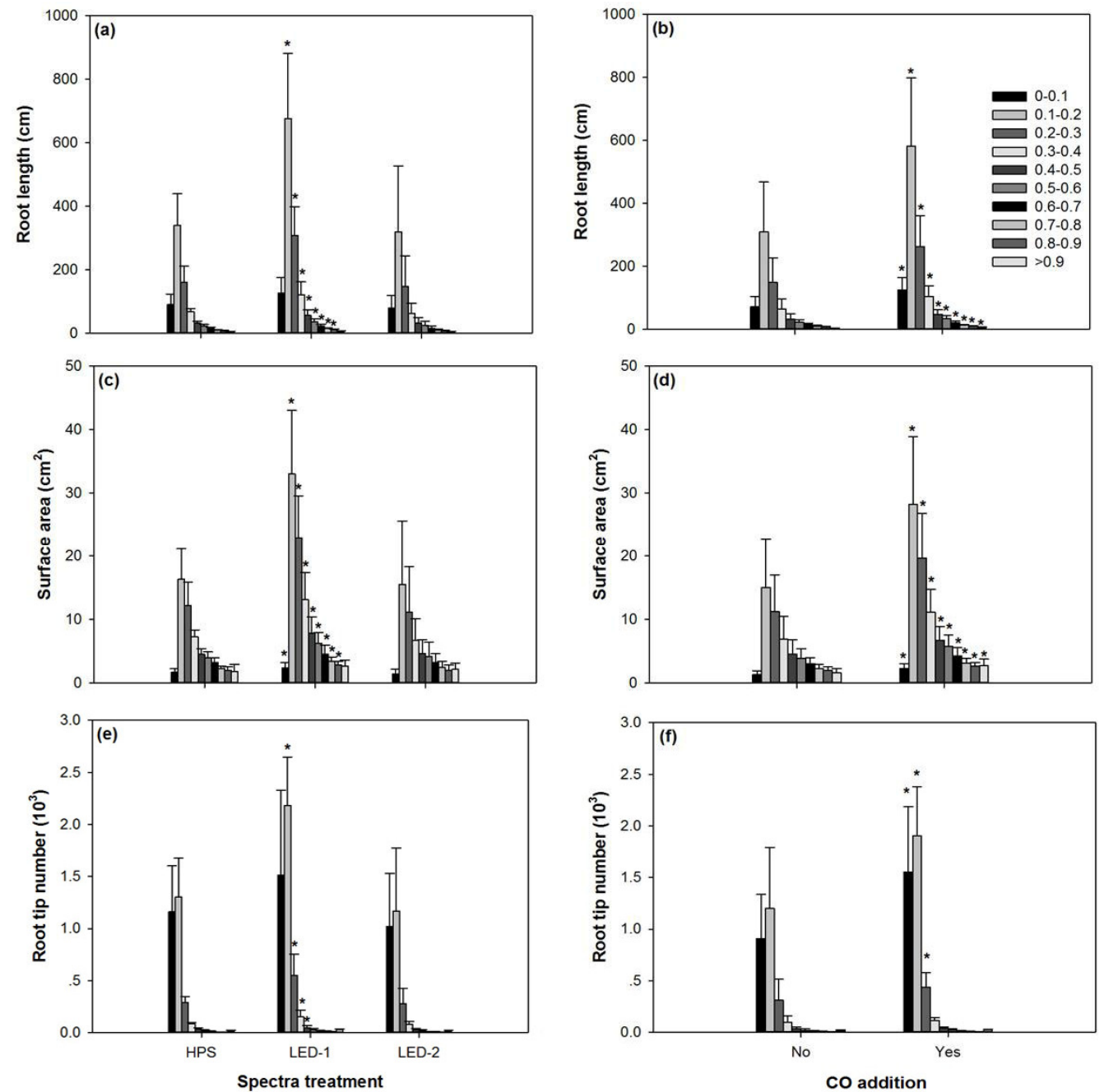

Figure 2. Fine root morphological parameters of length ( $a$ and b), surface area (c and d), and tip number (e and $\mathrm{f}$ ) in different diameter classes (legend unit: $\mathrm{mm}$ ) in Eleuthero (E. senticosus [Rup. \& Max.] Max.) seedlings with chitosan oligosaccharide (CO) addition at rates of $0(\mathrm{No})$ and $25 \mathrm{ppm}(\mathrm{Yes})$ under light spectra from high-pressure sodium (HPS) lamps and two light-emit diodes (LEDs) panels. Asterisks indicate significant difference between HPS and LED-1 treatments or between with and without CO addition treatments 


\section{The relationship among root growth parameters}

Coupled linear correlations indicated that any two root morphological parameters had a positive relationship between each other (Table 2). Also, positive correlation was found between root morphological parameter and dry weight. In detail, the relationship among fine root morphologies in different diameter classes can be described by the PCA model (Figure 3). The first PC accounted for $79.25 \%$ of the total data variation and the second PC accounted for $10.35 \%$. In the axis of PC-1, data about fine root length and surface area in all diameter classes showed high tendency to each other (Figure 3). These data were also closely accompanied by high eigenvalues of root tip numbers in diameter classes from 0 to $0.4 \mathrm{~mm}$. In the second PC axis, root tip number in diameter class of $0.5-0.6 \mathrm{~mm}$ was accompanied by negative eigenvalues for root tip number in diameter classes from 0.6 to $0.9 \mathrm{~mm}$ (Figure 3).

Table 2. Pearson correlations between couples of root diameters in Eleuthero (E. senticosus [Rupr. \& Maxim.] Maxim.) cultured under three spectrums with or without $\mathrm{CO}$ addition

\begin{tabular}{|c|c|c|c|c|c|}
\hline & Root length & Surface area & Diameter & Tip number & Dry weight \\
\hline \multirow{2}{*}{ Root length } & - & - & - & - & - \\
\hline \multirow{2}{*}{ Surface area } & $R=0.9967$ & - & - & - & - \\
& $P<0.0001$ & $R=0.9578$ & $R=0.9370$ & & - \\
Diameter & $P=0.0026$ & $P=0.0058$ & & - & - \\
& $R=0.9487$ & $R=0.9548$ & $R=0.8660$ & & - \\
\hline \multirow{2}{*}{ Tip number } & $P=0.0039$ & $P=0.0030$ & $P=0.0257$ & - & - \\
\hline \multirow{2}{*}{ Dry weight } & $R=0.9866$ & $R=0.9894$ & $R=0.9224$ & $R=0.9606$ & \\
& $P=0.0003$ & $P=0.0002$ & $P=0.0088$ & $P=0.0023$ & \\
\hline
\end{tabular}

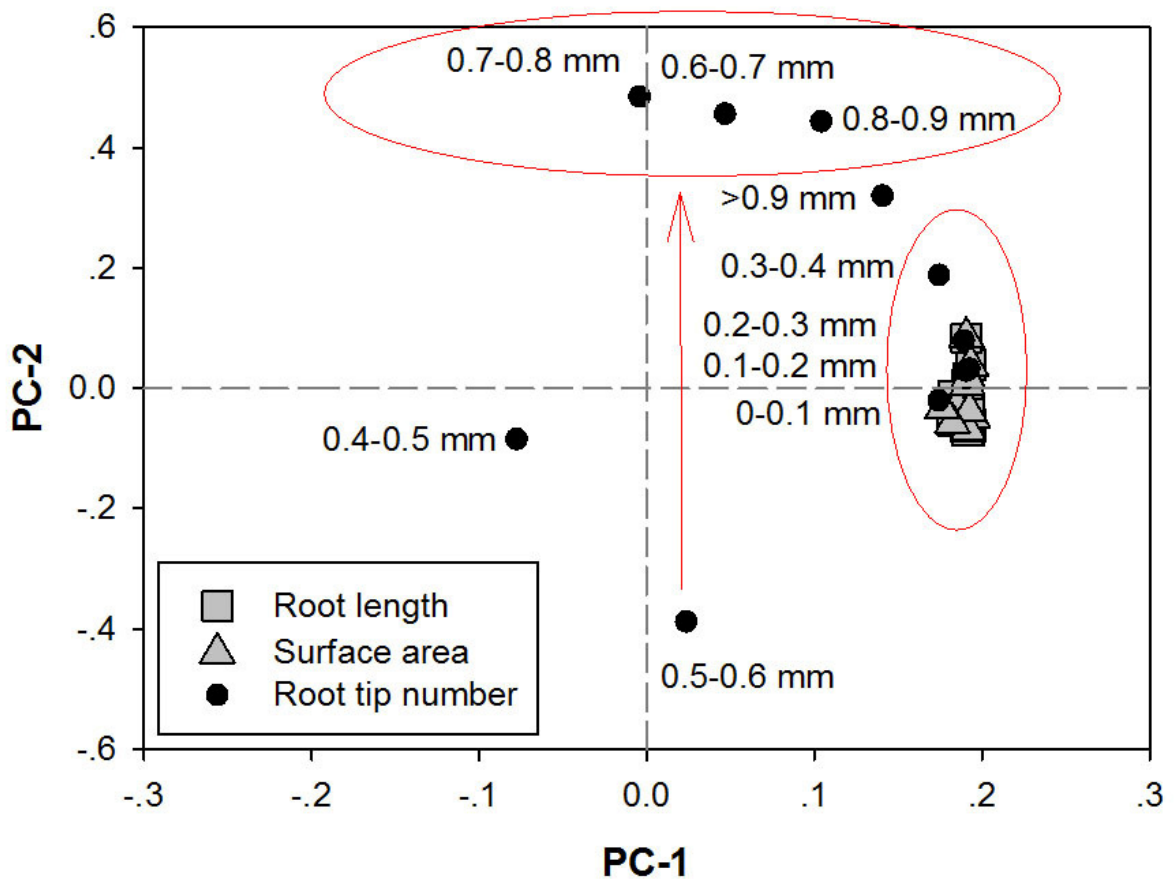

Figure 3. Principle component (PC) analysis on fine root morphological parameters of length, surface area, and tip number in Eleuthero (E. senticosus [Rup. \& Max.] Max.) seedlings 


\section{Discussion}

Our results disagreed with our first hypothesis. However, our results revealed significant main effects from either treatment on all root parameters. These results do not agree with Wang et al. (2017), who found an interactive effect of combined first-year $\mathrm{CO}$ addition and photoperiod on the second-year new-root-number in Buddhist pine seedlings. Authors therein demonstrated the nutrient dynamic across years and suggested that the over-year interactive effect on roots was caused by the inherent nutrient cycling. Further studies are suggested to continuously test the interactive effect of $\mathrm{CO}$ addition and light spectra on nutrient allocation during culture of Eleuthero seedlings to detect the possible mechanism of null interaction on root growth.

The PPFD for Eleuthero seedlings in our study $\left(94 \pm 5 \mu \mathrm{mol} \mathrm{m}^{-2} \mathrm{~s}^{-1}\right)$ was supplied continuously for $16 \mathrm{~h}$ every day. This light intensity was much lower than that $\left(250 \mu \mathrm{mol} \mathrm{m}^{-2} \mathrm{~s}^{-1}\right)$ in the continuous lighting for Norway spruce (Picea abies) and Scots pine (P. sylvestris) seedlings but close to that $\left(70-80 \mu \mathrm{mol} \mathrm{m}^{-2} \mathrm{~s}^{-1}\right)$ used as supplementary lighting for conifer species from temperate zones (Apostol et al., 2015) and that $(72-73 \mu \mathrm{mol}$ $\mathrm{m}^{-2} \mathrm{~s}^{-1}$ ) used in continuous lighting for fragrant rosewood seedlings ( $\mathrm{Li}$ et al., 2017a, 2018). Eleuthero is an undergrowth species and highly shade-tolerant; thus, a low light intensity is suitable for its growth and development.

Compared to the spectrum from HPS lamps, that from LED lighting resulted in larger root morphology and greater dry weight. In other studies, using HPS spectrum as the control, Riikonen et al. (2016) found that the LED spectrum of $75 \% \mathrm{R}$ and $25 \% \mathrm{~B}$ can increase root to shoot biomass ratio compared to that from HPS. However, Riikonen (2016) reported greater root biomass in Scots pine seedlings under 25\%B/R LED lighting than under HPS lamps. In addition, neither Apostol et al. (2015) nor Li et al. (2018) found significant change of root biomass under LED spectra compared to that under HPS lamps. Therefore, taking seedlings as materials, Eleuthero was more sensitive to light spectra in root growth than most of the tree species in current studies. Because root is one of the main organs with abundant pharmacological compounds for Eleuthero seedlings (Sun et al., 2011; Zhai et al., 2017), the LED lighting with the spectrum of $43.8 \% \mathrm{R} / 47 \% \mathrm{G} / 9.2 \% \mathrm{~B}$ can be considered for use with the purpose of promoting fine root elongation in this species.

Our results showed that the addition of $\mathrm{CO}$ can promote root dry weight and fine root morphology, which concur with former findings about plant root growth in response to $\mathrm{CO}$ addition (AleksandrowiczTrzcińska et al., 2015; Chamnanmanoontham et al., 2015; Zong et al., 2017). Nevertheless, Li et al. (2018) found no effect of $\mathrm{CO}$ addition on root dry weight in fragrant rosewood. These varied results are caused by the difference of plant species and the dose of $\mathrm{CO}$. Future work is needed to detect the deeper mechanism for the effect of $\mathrm{CO}$ addition on root growth in Eleuthero seedlings.

Our results about correlation between fine root variables across diameters suggested that surface area grew with the increase of root elongation. Root length and surface area in transplanted Buddhist pine and Northeast yew (Taxus cuspidata) seedlings also showed high similarity (Wei et al., 2017). Similar results were also reported during the first-year culture of Northeast yew seedlings (Zhao et al., 2017). Root tip in diameter of 0-0.4 $\mathrm{mm}$ accounted for the main response among all fine roots. They also showed highly positive relationships with root length and surface area, suggesting that new egress of very fine roots contributed to the length and area growth in Eleuthero seedling roots. According to the study on morphological and anatomical relationship of loblolly pine trees, fine roots in diameter $<0.5 \mathrm{~mm}$ were mostly white new roots and those in diameter between 0.5 and $1 \mathrm{~mm}$ mostly changed to be woody with orange or brown colour (McCrady and Comerford, 1998). In Eleuthero seedling roots, the root tip number varied depending on the relationship with length and surface area in different diameters likely because of their different functions. Therefore, we can accept our second hypothesis. 


\section{Conclusions}

Treatments of CO addition and light spectra had no interactive effect on root growth parameters in Eleuthero seedling roots. Instead, either treatment had a main effect on root morphology and dry weight. Compared to the light spectrum (43.7\% R:54.6\% G:1.7\% B) from HPS lamps, that of 43.8\% R:47\% G:9.2\% B from LED resulted in greater root dry weight and morphology by over $30 \%$. The $\mathrm{CO}$ addition would also increase root growth by $40-70 \%$. Fine roots in diameter between $0-0.4 \mathrm{~mm}$ were the main root part that contributed to the length, surface area, and new root number. Therefore, LED lighting can be used for the culture of Eleuthero seedlings with the purpose of promoting dry weight and morphology of fine roots.

\section{Acknowledgements}

This study was financially supported by the National Key Technologies R\&D Program of China (grant number 2016YFC0500300), National Natural Science Foundation of China (grant number 41971122), and National survey on Chinese Materia Medica Resources by National Administration of Traditional Chinese Medicine (grant number GZY-KJS-2018-004).

\section{Conflict of Interests}

The authors declare that there are no conflicts of interest related to this article.

\section{References}

Aleksandrowicz-Trzcińska M, Bogusiewicz A, Szkop M, Drozdowski S (2015). Effect of chitosan on disease control and growth of Scots pine (Pinus sylvestris L.) in a forest nursery. Forests 6:3165-3176. https://doi.org/10.3390/f6093165

Apostol KG, Dumroese RK, Pinto JR, Davis AS (2015). Response of conifer species from three latitudinal populations to light spectra generated by light-emitting diodes and high-pressure sodium lamps. Canadian Journal of Forest Research 45:1711-1719. https://doi.org/10.1139/cjfr-2015-0106

Chamnanmanoontham N, Pongprayoon W, Pichayangkura R, Roytrakul S, Chadchawan S (2015). Chitosan enhances rice seedling growth via gene expression network between nucleus and chloroplast. Plant Growth Regulation 75:101-114. https://doi.org/10.1007/s10725-014-9935-7

Duan J, Xu CY, Jacobs DF, Ma LY, Wei HX, Jiang LN, Ren J (2013). Exponential nutrient loading shortens the cultural period of Larix olgensis seedlings. Scandinavian Journal of Forest Research 28(5):409-418. https://doi.org/10.1080/02827581.2013.778328

Guo SL, Wei HX, Li JP, Fan RF, Xu MY, Chen X, Wang ZY (2019). Geographical distribution and environmental correlates of eleutherosides and isofraxidin in Eleutherococcus senticosus from natural populations in forests at Northeast China. Forests 10(10): 872. https://doi.org/10.3390/f10100872

Khan WM, Prithiviraj B, Smith DL (2002). Effect of foliar application of chitin and chitosan oligosaccharides on photosynthesis of maize and soybean. Photosynthesis 40(4):621-624. https://doi.org/10.1023/A:1024320606812

Jeong GT, Park DH (2005). Enhancement of growth and secondary metabolite biosynthesis: Effect of elicitors derived from plants and insects. Biotechnology and Bioprocess Engineering 10:73-77. https://doi.org/10.1007/BF02931186

Li XW, Gao Y, Wei HX, Xia HT, Chen QX (2017a). Growth, biomass accumulation and foliar nutrient status in fragrant rosewood (Dalbergia odorifera TC Chen) seedlings cultured with conventional and exponential fertilizations 
under different photoperiod regimes. Soil Science and Plant Nutrition 63(2):153-162. https://doi.org/10.1080/00380768.2017.1312518

Li Y, Xin GF, Min W, Shi QH, Yang FJ, Wang XF (2017b). Carbohydrate accumulation and sucrose metabolism responses in tomato seedling leaves when subjected to different light qualities. Scientia Horticultae 225:490-497. https://doi.org/10.1016/j.scienta.2017.07.053

Li XW, Chen QX, Lei HQ, Wang JW, Yang S, Wei HX (2018). Nutrient uptake and utilization by fragrant rosewood (Dalbergia odorifera) seedlings cultured with oligosaccharide addition under different lighting spectra. Forests 9:29. https://doi.org/10.3390/f9010029

McCrady RL, Comerford NB (1998). Morphological and anatomical relationships of loblolly pine fine roots. Trees Structure \& Function 12:431-437. https://doi.org/10.1007/s004680050171

Riikonen J (2016). Pre-cultivation of Scots pine and Norway spruce transplant seedlings under four different light spectra did not affect their field performance. New Forests 47(4):607-619. https://doi.org/10.1007/s1 1056-016-9533-9

Riikonen J, Kettunen N, Gritsevich M, Hakala T, Särkkä L, Tahvonen R (2016). Growth and development of Norway spruce and Scots pine seedlings under different light spectra. Environmental and Experimental Botany 121:112120. https://doi.org/10.1016/j.envexpbot.2015.06.006

Sun YL, Liu LD, Hong SK (2011). Eleutherococcus senticosus as a crude medicine: Review of biological and pharmacological effects. Journal of Medical Plant Research 5(25):5946-5952. DOI: 10.5897/JMPR11.728

Wan JZ, Wang CJ, Yu JH, Nie SM, Han SJ, Liu JZ, Zu YG, Wang QG (2016). Developing conservation strategies for Pinus koraiensis and Eleutherococcus senticosus by using model-based geographic distributions. Journal of Forestry Research 27(2):389-400. https://doi.org/10.1007/s11676-015-0170-5

Wang YJ, Wei HX, Ge LL, Sun NW, Wang T, Zhang QC, Han LB, Ge XY, Jin GY (2018). Chitosan oligosaccharide addition modifies nutrient utilization in highly-valued ornamental tree seedlings. Forestry \& Environmental Science 34(3):136-144.

Wang Z, Zhao Y, Wei HX (2017). Chitosan oligosaccharide addition affects current-year shoot of post-transplant Buddhist pine (Podocarpus macrophyllus) seedlings under contrasting photoperiods. iForest - Biogeosciences \& Forestry 10:715-721. https://doi.org/10.3832/ifor2302-010

Wei HX, Xu CY, Ren J, Ma LY, Duan J, Jiang LN (2013a). Newly transplanted Larix olgensis Henry stock with greater root biomass has higher early nitrogen flux rate. Soil Science and Plant Nutrition 59(5):740-749. https://doi.org/10.1080/00380768.2013.816977

Wei HX, Ren J, Zhou JH (2013b). Effect of exponential fertilization on growth and nutritional status in Buddhist pine (Podocarpus macrophyllus [Thunb.] D. Don) seedlings cultured in natural and prolonged photoperiods. Soil Science and Plant Nutrition 59(6):933-941. https://doi.org/10.1080/00380768.2013.864957

Wei HX, Guo P, Zheng HF, He XY, Wang PJ, Ren ZB, Zhai C (2017). Micro-scale heterogeneity in urban forest soils affects fine root foraging by ornamental seedlings of Buddhist pine and Northeast yew. Urban Forestry \& Urban Greening 28:63-72. https://doi.org/10.1016/j.ufug.2017.10.006

Wei HX, Hauer RJ, Chen GS, Chen X, He XY (2020). Growth, nutrient assimilation, and carbohydrate metabolism in Korean pine (Pinus koraiensis) seedlings in response to light spectra. Forests 11(1):44. https://doi.org/10.3390/f11010044

Zaluski D, Smolarz HD (2016). Influence of Polish climate conditions on content and the chemical variation of volatiles in the roots of six Eleutherococcus species and their potential use. Recent Natural Products 10(2):240-244.

Zhai CM, Wang M, Raman V, Rehman JU, Meng YH, Zhao JP, ... Khan IA (2017). Eleutherococcus senticosus (Araliaceae) leaf morpho-anatomy, essential oil composition, and its biological activity against Aedes aegypti (Diptera: Culicidae). Journal of Medical Entomology 54(3):658-669. https://doi.org/10.1093/jme/tjw221

Zhao J, Chen X, Wei HX, Lv J, Chen C, Liu XY, ... Jia LM (2019). Nutrient uptake and utilization in Prince Rupprecht's larch (Larix principis-rupprechtii Mayr.) seedlings exposed to a combination of light-emitting diode spectra and exponential fertilization. Soil Science and Plant Nutrition 65(4):358-368. https://doi.org/10.1080/00380768.2019.1631715

Zhao Y, Wang Z, Wei HX, Bao YJ, Guo P (2017). Effect of prolonged photoperiod on morphology, biomass accumulation and nutrient utilization in post-transplant Taxus cuspidata seedlings. Pakistan Journal of Botany 49(4):1285-1290. 
Zong HY, Liu S, Xing RG, Chen XL, Li PC (2017). Protective effect of photosynthesis and antioxidative defense system in edible rape (Brassica rapa L.) in the presence of cadmium. Ecotoxicology and Environment Safety 138:271278. https://doi.org/10.1016/j.ecoenv.2017.01.009
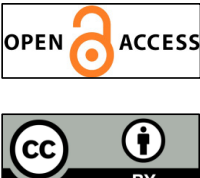

The journal offers free, immediate, and unrestricted access to peer-reviewed research and scholarly work. Users are allowed to read, download, copy, distribute, print, search, or link to the full texts of the articles, or use them for any other lawful purpose, without asking prior permission from the publisher or the author.

License - Articles published in Notulae Botanicae Horti Agrobotanici Cluj-Napoca are Open-Access, distributed under the terms and conditions of the Creative Commons Attribution (CC BY 4.0) License.

(c) Articles by the authors; UASVM, Cluj-Napoca, Romania. The journal allows the author(s) to hold the copyright/to retain publishing rights without restriction. 